\title{
LA CRISIS Y EL MOVIMIENTO SINDICAL EN LA TRANSICION SALVADOREÑA
}

\section{Rafael Guido Bejar1}

¿Qué ha sucedido en el mundo laboral y sindical durante el período de cumplimiento de los Acuerdos de Paz? ¿Cómo han influido éstos últimos en la dinámica de la oferta y demanda de fuerza de trabajo en El Salvador? ¿Qué ha producido a nivel del movimiento laboral la articulación de la globalización con las modificaciones económicas y políticas internas del país? ¿Cuál es y cómo puede evolucionar la situación del trabajo en esta nueva fase dedesarrollo? ¿Qué impactos, qué modificaciones, pueden apreciarse en los sindicatos en este importante lapso? ¿Qué tendencias sindicales emergen en el tiempo de la reconstrucción nacional de post-guerra?

I. ¿De dónde ha provenido el conflicto laboral post-acuerdos?

T as turbulencias sociales del período postacuerdos han tenido Lcomo actores importantes a las fuertes movilizaciones de trabajadores de los sectores públicos (Ministerios de Hacienda, Educación, Salud, Anda, Seguro Social, etc.); de las obreras en las zonas maquiladoras y, en menor medida, de los sindicatos de empresas privadas tradicionales. Los sindicatos y asociaciones pro-

1. Jefe del Departamento de Sociología y Ciencias Políticas de la Universidad Centroamericana "José Simeón Cañas" - (UCA) - de El Salvador. 
testan por el irrespeto a los derechos sindicales, a los malos tratos en las empresas, a los despidos arbitrarios (como las trabajadoras de las maquilas).

Grandes contingentes se manifiestan en busca de trabajo y de ingresos. Muchos grupos, como los desmovilizados de ambos grupos militares de la guerra, los olvidados de la paz (los integrantes de importantes cuerpos para-estatales y para-militares llamados patrullas civiles que no fueron contemplados en los acuerdos), los lisiados, los tenedores de tierras en las ex-zonas conflictivas, es decir los beneficiarios directos de los acuerdos reclaman sus dividendos de la paz que no son cumplidos como se esperaba. Son los primeros movimientos de desempleados en la historia laboral del país que se movilizan ejerciendo una presión nunca antes vista en los grupos de desocupados.

Los cooperativistas, los cuentapropistas (como los pequeños y medianos empresarios del transporte, los vendedores ambulantes de distintas zonas urbanas), los trabajadores de las empresas estatales próximas a ser privatizadas (sindicatos de trabajadores de telecomunicaciones, agua y hospitales) rechazan esta posibilidad y se manifiestan en las calles de la capital salvadoreña aunque sin plantear alternativas viables y factibles. La Policía Nacional Civil ha efectuado en contra de todos estos grupos, cada vez con mayor dureza, acciones repesivas que recuerdan los tiempos pre-acuerdos.

Se agrega a este clima de malestar social, la intranquilidad de la población civil frente a las distintas acciones de la delincuencia común y el crimen organizado. Gobierno y partidos políticos de oposición han considerado estas formas de expresión social como componentes de ingobernabilidad y hasta de desestabilización del nuevo "orden democrático" en construcción. Frente a estos problemas se pide mayor eficiencia policial y se mira con agrado que la Fuerza Armada, con el plan "Guardián", se integre a las tareas de controlar la seguridad pública. Separar a la Fuerza Armada de éste ámbito fue un punto central de la desmilitarización de los acuerdos de paz.

\section{La situación en el ámbito laboral}

$\Psi^{n}$ el mismo período, por otra parte, sectores importantes de 
los trabajadores han mostrado capacidad y voluntad de negociación y tolerancia al participar con los empresarios y estado en el fugaz y ahora extinto FORO ECONÓMICO-SOCIAL, nacido de los Acuerdos de Paz.

El Foro fue concebido por los Acuerdos como un espacio para la discusión tripartita (trabajadores, empresarios y estado) sobre los grandes problemas socioeconómicos del país, para la concertación del desarrollo nacional y la solución negociada de los conflictos entre las partes. Se abrió así un ambiente favorable para la renovación del marco legal laboral a la cual, en efecto, se avocaron las partes luego de integrarse el FORO no sin grandes dificultades.

El Foro Económico-social tuvo una vida real muy efímera ( 7 meses aproximadamente) al ser sustituido muy pronto por el CONSEJO NACIONAL DEL TRABAJO (Ver Tabla No. 1), una instancia estatal más cercana a la concepción empresarial y del sector gubernamental, que con gran dificultad mantiene la posibilidad para la concertación y el pacto sociales posteriores.

En el Foro se discutieron e introdujeron importantes modificaciones al Código del Trabajo, aunque las reformas finales fueron presentadas por el Estado incorporando sólo partes de estas discusiones. El Foro no se volvió a reunir y ante la fecha límite que EUA había fijado para que El Salvador llenara los requisitos internacionales para gozar del Sistema General de Preferencias, el GOES presentó el proyecto de modificaciuones de una manera unilateral. En general, el empresariado y el Estado habían aceptado ya las normativas de la OIT que desde hace muchos venían rechazando. (Ver Tabla No. 2). 
TABLA No. 1

PRINCIPALES FECHAS DEL FORO SOCIO-ECONOMICA

\begin{tabular}{|l|l|l|}
\hline No & $\begin{array}{l}\text { FECHAS IMPORTAN- } \\
\text { TES DEL FORO }\end{array}$ & \multicolumn{1}{|c|}{ ASUNTO TRATADO } \\
\hline 1 & Enero 16, 1992 & $\begin{array}{l}\text { Firma de los Acuerdos de Paz que contenian } \\
\text { el Foro para la Concertación Económica y } \\
\text { Social. }\end{array}$ \\
\hline 2 & Septiembre, 1992 & Integración del Foro \\
\hline 3 & Febrero 17, 1993 & $\begin{array}{l}\text { "Acuerdo de Principios y Compromisos" } \\
\text { para superar la improductividad del Foro }\end{array}$ \\
\hline 4 & Mayo 21, 1993 & $\begin{array}{l}\text { Inicio de funcionamiento. Empresarios decla- } \\
\text { ran inconstitucionales a los convenios de la } \\
\text { OIT referidos a la libertad y derechos de } \\
\text { sindicación y al contrato colectivo. }\end{array}$ \\
\hline 5 & Octubre, 1993 & $\begin{array}{l}\text { Dos delegados de la OIT, Arturo Bronstein y } \\
\text { Enrique Marín, a petición de las partes llega- } \\
\text { ron al país para asesorar en las reformas (pro- } \\
\text { pusieron las reformas de 48 artículos) y fun- } \\
\text { cionamiento estatal laboral }\end{array}$ \\
\hline 6 & Agosto 25, 1993 & $\begin{array}{l}\text { Firma del "Documento para el desarrollo y } \\
\text { operatividad del Acuerdo de Pricipios y } \\
\text { Compromisos sobre el Tema marco Legal } \\
\text { Laboral" }\end{array}$ \\
\hline 7 & Diciembre 9, 1993 & $\begin{array}{l}\text { Ultima reunión del FORO. Empresarios y } \\
\text { GOES ante la dinámica electoral del 94, de- } \\
\text { cidieron suspenderlo para evitar su } \\
\text { politización. Se habian logrado acuerdos so- } \\
\text { bre 18 reformas, acuerdos en principio so- } \\
\text { bre 18 y diferencias en 8. }\end{array}$ \\
\hline 9 & Abriembre 13,1993 21,1994 & $\begin{array}{l}\text { GOES, en forma unilateral, presenta a la } \\
\text { Asamblea una propuesta distinta de modi- } \\
\text { ficaciones al Código de Trabajo, contenien- } \\
\text { do algunas del FORO }\end{array}$ \\
\hline $\begin{array}{l}\text { Aprobación legislativa (Decreto No. 859) de } \\
\text { la propuesta del ajecutivo. }\end{array}$ \\
\hline
\end{tabular}




\section{CONVENIOS DE LA OIT APROBADOS POR EL FOROS SOCIOECONOMICO.}

EL SALVADOR. 1993

\begin{tabular}{|l|l|l|}
\hline No. & $\begin{array}{l}\text { CONVENIOS DE LA OIT } \\
\text { APROBADOS POR EL } \\
\text { FORO }\end{array}$ & No. DE CONVENIO \\
\hline 1 & Libertad de sindicación & 143 \\
\hline 2 & Salario mínimo & 99,131 \\
\hline 3 & Consultas tripartitas & 144 \\
\hline 4 & Empleo & $88,122,142$ \\
\hline 5 & Trabajo de menores & $10,77,78,138$ \\
\hline 6 & Trabajo de mujeres & 111 \\
\hline 7 & Inspección del trabajo & 81,129 \\
\hline
\end{tabular}

De nuevo, por diversas razones, el estado no trabaja con las decisiones elaboradas y discutidas por los sindicalistas y funciona con las elaboraciones de sus propias instancias que aunque incorporan resultados del FORO son muy diferentes. ¿Continúa el no reconocimiento de los representantes del trabajo como actores de la normatividad y del marco político-jurídico del nuevo orden laboral salvadoreño? ¿Ha sido un signo de continuidad de la exclusión laboral?

El estado, al final de cuentas, sustituyó a los trabajadores y a los empresarios y propuso por su propia cuenta la redacción final $y$, en cierto modo, los contenidos del articulado de las reformas al Código de Trabajo. La representación y participación de los obreros, en ese sentido, continúan siendo mediatizadas por el estado y sin una relación propia con la legalidad laboral pertinente al orden económico del país. 


\title{
2. La situación en el ámbito empresarial
}

\begin{abstract}
T os empresarios, por su lado, han modernizado sus expresiones y aspiraciones. En sus discursos y frecuentes actividades de socialización de sus nuevas ideas plantean la necesidad de ser competitivos y alcanzar grados de eficiencia y eficacia a nivel internacional, elevar las tasas de inversión, atraer la inversión extranjera y de crear nuevos sistemas y servicios financieros para la renovación y reconversión del parque industrial, búsqueda de mayores niveles tecnológicos y científicos, mejorar la educación primaria, secundaria y superior, actualizar la capacitación técnica, abrir mercados regionales, integración centroamericana, etc.
\end{abstract}

Han dedicado importantes esfuerzos e inversiones a crear centrós nuevos para la capacitación obrera, universidades e institutos superiores para formar cuadros gerenciales y de dirección media, modernizar o crear nuevos medios de comunicación, etc. Es indudable que todas estas actividades repercutirán y cambiarán las relaciones industriales, empresariales, laborales y sindicales del país. Otros proyectos como la privatización, la descentralización, la integración centroamericana, y la modernización del Estado promoverán más cambios significativos en el futuro.

La economía salvadoreña en general muestra una transformación que tendrá impactos trascendentales en toda la vida y organización sociales del país. La pérdida de dinamismo irreversible de la agroexportación tradicional, la irrelevancia relativa hasta el momento de las exportaciones no tradicionales, la crisis irrecuperable del modelo industrial de sustitución de importaciones, son características que llenan de incertidumbre a los distintos sectores productivos del país. El crecimiento del sector servicios y la estrategia de promoción de exportaciones (en la rama de maquilas) se perfilan como los sectores más ágiles y en los que se busca encontrar la nueva dinámica de la acumulación económica.

\section{c. La situación estatal y política al respecto}

El programa económico gubernamental está aún en proceso de elaboración como el mismo rumbo económico de país. El gobierno ha tomado distintas medidas macroeconómicas pero no ha articulado un programa real para el desarrollo económico. Las medidas 
asumidas han sido objeto de discusiones y descontentos por parte de diferentes sectores empresariales y populares y han provocado discrepancias políticas y modificaciones en las anteriores alineaciones partidarias.

El Pacto de San Andrés (mayo 1995), conteniendo una larga agenda de reformas económicas y administrativas, ha sido firmado sólo por el gobiemo, un partido legal -ARENA - y un partido en formación pero con representación parlamentaria - PDmostrando las dificultades que existen en la sociedad para un acuerdo económico y una mínima voluntad política de unidad. Los intereses empresariales en juego, quizás no muy distintos, al menos tienen visiones muy encontradas y desconfianzas tradicionales entre los principales actores.

En el plano político también se pueden apreciar los impactos de estos problemas y las distintas tendencias que los distintos grupos proponen para solucionarlos. Por ejemplo, los alineamientos de los partidos opositores (PDC y PCN) que formaban coaliciones con el gobernate Arena y que estan vinculados con distintos sectores empresariales han cambiado significativamente. Ahora se aproximan a partidos y grupos de presión con los cuales tenían oposiciones abismales.

La discusión socialdemócrata (la que gira en torno a las nuevas relaciones entre los empresarios, trabajadores y estado) en El Salvador dió contenido a una disputa ideológica y política, mucho más larga e histórica, entre las izquierdas hasta culminar en una división del Frente Farabundo Martí para la Liberación Nacional (FMLN) del cual se desprendió una línea que ha optado por la socialdemocra-cia, el Partido Demócrata (PD). Concepciones, métodos de movilización, procedimientos y formas de relación se discuten en esta disputa que ha debilitado a la oposición en general, pero en especial a la de la de izquierda.

\section{d. ¿Más de lo mismo?}

No obstante, el malestar social persiste. ¿Por qué coexisten estas dos situaciones? ¿Modernización, por un lado, y comportamiento tradicional contra el movimiento social -en especial al laboral, por otro? ¿Qué explicaciones pueden darse frente a una realidad 
cambiante que mantiene prácticas del pasado? ¿Cómo se relacionan los distintos movimientos sociales con esta redefinición de los mercados de trabajo y con las nuevas estructuras políticas del país?

CUADRO No. 1

PRINCIPALES MOTIVOS DE CONFLICTOS LABORALES POR SECTOR. EL SALVADOR. 1993-94

\begin{tabular}{|c|c|c|c|}
\hline No & $\begin{array}{l}\text { MOTIVO DEL } \\
\text { CONFLICTO }\end{array}$ & $\begin{array}{l}\text { SECTOR } \\
\text { PRIVADO }\end{array}$ & $\begin{array}{l}\text { SECTOR } \\
\text { PUBLICO }\end{array}$ \\
\hline 1 & $\begin{array}{l}\text { Demanda de incremento sa- } \\
\text { larial }\end{array}$ & 1 & 29 \\
\hline 2 & $\begin{array}{l}\text { Incumplimiento de acuerdo } \\
\text { laborales anteriores }\end{array}$ & 2 & 14 \\
\hline 3 & Inestabilidad laboral & 12 & \\
\hline 4 & $\begin{array}{l}\text { Privatización de empresa y/ } \\
\text { o servicios públicos }\end{array}$ & & 8 \\
\hline 5 & Despidos & 16 & 11 \\
\hline 6 & Retraso pago de salarios & & 5 \\
\hline 7 & $\begin{array}{l}\text { Problemas con jefes superio- } \\
\text { res }\end{array}$ & & 5 \\
\hline 8 & $\begin{array}{l}\text { Demanda de prestaciones so- } \\
\text { cio-laborales y mejores condi- } \\
\text { ciones de trabajo }\end{array}$ & 12 & 13 \\
\hline 9 & $\begin{array}{l}\text { Divisiones internas entre } \\
\text { organizaciones laborales }\end{array}$ & & 4 \\
\hline 10 & $\begin{array}{l}\text { Negociación de contrato } \\
\text { colectivo }\end{array}$ & & 1 \\
\hline 10 & Otros & 4 & 7 \\
\hline 11 & TOTAL & 35 & 109 \\
\hline
\end{tabular}

Fuente: FES 1993 y 1994 
¿Por qué la movilización social -en especial la del sector obrero - mantiene las mismas características anteriores- en las formas tradicionales de manifestaciones violentas, tomas de fábricas y de mantener como rehenes a los empresarios, huelgas de hecho, etc., - y las demandas parecieran ser las mismas - empleo, mejora de las condiciones y prestaciones sociales, vigencia de los derechos laborales y humanos, contratos colectivos casi inalcanzables, lucha contra la inflación?

CUADRO No. 2

ACCION SINDICAL. EL SALVADOR. 1993-94.

\begin{tabular}{|l|c|c|c|c|c|c|}
\hline $\begin{array}{l}\text { ACTIVIDADES } \\
\text { LABORALES }\end{array}$ & \multicolumn{2}{|l|}{$\begin{array}{l}\text { SECTOR } \\
\text { PRIVADO }\end{array}$} & \multicolumn{2}{|c|}{$\begin{array}{l}\text { SECTOR } \\
\text { PUBLICO }\end{array}$} & \multicolumn{2}{l|}{ TOTAL } \\
\hline & 93 & 94 & 93 & 94 & 93 & 94 \\
\hline Conflictos laborales & 40 & 6 & 38 & 27 & 78 & 33 \\
\hline Huelgas & 19 & 1 & 14 & 32 & 20 & 33 \\
\hline Acciones de calle & 4 & 4 & 3 & 9 & 7 & 13 \\
\hline
\end{tabular}

Fuente: Fes, 1993 y 1994

La arena laboral continúa muy agitada y cada vez más se evidencian conflictos donde la violencia es el rasgo más importante. En el 93, los trabajadores del sector privado fueron los dinamizadores de las acciones sindicales. En el 94, lo empleados públicos habían superado considerablemente a los primeros incrementando considerablemente las huelgas y las acciones de calle. Esta pauta continúa en el 95 a tal grado que la Policía Nacional Civil aumenta la intensidad de represión que ha sido objeto de preocupación y críticas por parte de distintos sectores de la sociedad salvadoreña, temiéndose que la PNC haya olvidado su misión y objetivos iniciales en los Acuerdos de Paz.

Una rara situación. Los empresarios manifiestan estar de acuerdo con mejorar las condiciones laborales aunque en los momentos de discutir el contrato colectivo o mejoramientos de las condiciones de trabajo se oponen a los mismos por otra parte, los obreros 
han dado muestras de tolerancia y han negociado en los espacios que se han abierto pero al mismo tiempo utilizan los mismos métodos del pasado para hacer oir sus posiciones y propuestas. El Estado, así mismo, muestra flexibilidad frente a las presiones internacionales y modifica las normas laborales pero continúa sin aceptarlas de parte de los trabajadores con quienes mantiene un no reconocimiento virtual, como ya se dijo anteriormente.

\section{Una hipótesis en constitución}

$F^{n}$ la actualidad se exige del movimiento obrero y sindical una L modernización en su acción profesional y sindical mientras las condiciones de vida (socio-económicas, políticas y culturales) muestran signos inequívocos de un creciente deterioro.

La profunda crisis del movimiento sindical, su pérdida de peso en la vida política y social del país, el irrespeto a los mecanismos destinados a garantizar los derechos laborales y sindicales o las prestaciones de seguridad social, en especial en el sector nuevo de las maquiladoras, son algunos de los indicadores que muestran la desventajosa situación del trabajo en su relación con el capital y el estado. Debe agregarse la situación de incertidumbre que provoca la persistencia del sistema económico anterior muy debilitado, con claros signos de agotamiento, y la indecisión por definir las nuevas líneas para insertarse en el nuevo orden económico internacional.

La hipótesis que está en proceso de construcción para explicar la coexistencia de las formas modernas y antiguas en las relaciones laborales no sólo debe de apoyarse en la idea de que es un proceso de transición (en la que coexisten lo nuevo y lo viejo) pues también existen evidencias de mantener, en forma conciente, ciertas continuidades de la época que está por cerrarse, por lo menos en cuanto a la cuestión de la fuerza de trabajo se refiere. La hipótesis podría plantearse, de manera inicial, de la siguiente manera:

Los tradicionales usos de la fuerza de trabajo en El Salvador se reciclan y reintegran en los cambios provocados por los Acuerdos de Paz, la democratización, la orientación hacia la globalización, la estructura productiva y el mercado de trabajo salvadoreño. 
En otras palabras, los preparativos que hace la economía salvadoreña para acomodarse a la globalización se basan en la conservación de los mercados laborales fuertemente basados en el trabajo informalizado, acentuando cada vez más la reducción de la temporalidad de la contratación de la fuerza de trabajo, rasgos que ya estaban presentes en la organización productiva del periodo de la agro-exportación basada en la acumulación cafetalera. Estos rasgos se reprodujeron en la experiencia industrial del periodo terminado de sustitución de importaciones.

Esta última última siempre ha descargado o reducido al mínimo los costos de la reproducción social del trabajador y su familia que son cubiertos por la empresa y el estado -rasgo básico de la economía salvadoreña tradicional y base de la propuesta laboral del nuevo Pacto de San Andrés. Todo parece indicar que este rasgo continuará en el nuevo período de modernización y globalización.

\section{La segmentacion del mercado y el uso de la fuerza de trabajo salvadoreña}

\section{a. Características generales}

El problema básico de la actual economía y del desarrollo salvadoreños continúa siendo la oferta abundante de mano de obra, masculina y femenina, y la reducida absorción de mano de obra, real y potencial, del aparato productivo. A esta insoluble situación de la oferta laboral se agregan los problemas de la asignación salarial, la durabilidad laboral y las formas de contratación que estos rasgos dan lugar.

Las características básicas de la actual fuerza de trabajo: abundante, joven, crecientemente femenina y sin educación formal (más de la mitad de la PEA o no tiene ningún grado aprobado (12\%) ó tiene sólo estudios de primaria (41\%). Unicamente el $7 \%$ de la fuerza de trabajo empleada tiene bachillerato o más). Las mujeres muestran mayor intensidad a la integración al mercado informal con las siguientes características: sin prestaciones sociales, ingresos fluctuantes, alta inseguridad, horarios de trabajo semanales mayores que los oficiales y salarios menores al mínimo legal. 
En la actualidad ha decrecido en importancia y dinámica el sector agrícola y han aumentado el sector servicios y el industrial. En 1992 la mayor proporción de fuerza de trabajo empleada estaba en el sector servicios, con una población femenina que duplica al sector masculino. Estos rasgos han acentuado y/o generado una nueva organización del trabajo y de los mercados de trabajo.

\section{b. Uso de la fuerza de trabajo}

La tendencia de todos los mercados es a utilizar fuerza de trabajo informalizada que mantiene frente a las necesidades temporales del capital ofertas altamente elásticas. En el sector informal los cuentapropistas son un gran reservorio para los trabajos sin especialización y en el formal. También las pequeñas y medianas empresas mantienen enormes contingentes que en el momento de expansión, temporal o permanente, de las grandes empresas llegan a utilizar de una manera muy favorable.

Por otra parte, es muy importante la proporción en el cual todos los mercados mantienen un alto índice de asalariados temporales o eventuales que hace ver la tendencia a que esta característica se esté generalizando para la contratación de los trabajadores, tanto en la empresa privada como en la pública. El $58.5 \%$ de los ocupados en ambos mercados (formal e informal) no son asalariados permanentes

Aún en el sector formal los trabajadores temporales tienen un peso considerable ya que representan arriba del $20 \%$ de acuerdo al cuadro anterior que no recoje muy bien la temporalidad de los contratos ni sus jornadas de trabajo. Este dato debe completarse con otros muy importantes como son los de los contratos colectivos e individuales como una mejor forma para precisar la durabilidad de los contratos.

Los contratos colectivos son muy pocos. En 1993 existían unicamente 298 y comprendían unicamente a 61,471 trabajadores, es decir, el 3.74 de la población empleada $(1,642,214)$. La construcción y la manufactura son los que tienen los mayores números de contratos colectivos, 196 y 58 respectivamente. En 1994 sólo hubo un aumento de 7 contratos colectivos. Muy pocos de los contratos colectivos son registrados en el Ministerio de Trabajo para poder 


\section{CUADRO No. 3 \\ DISTRIBUCION DE OCUPADOS DEL MERCADO \\ FORMAL E INFORMAL POR TIPO DE OCUPACION. \\ AREA URBANA. EL SALVADOR. 1991. \\ (Absolutos y porcentajes)}

OCUPACION Y

TIPO DE

Cuen Prop No remun

Asalariado

MERCADO

Perm

Temporal Total

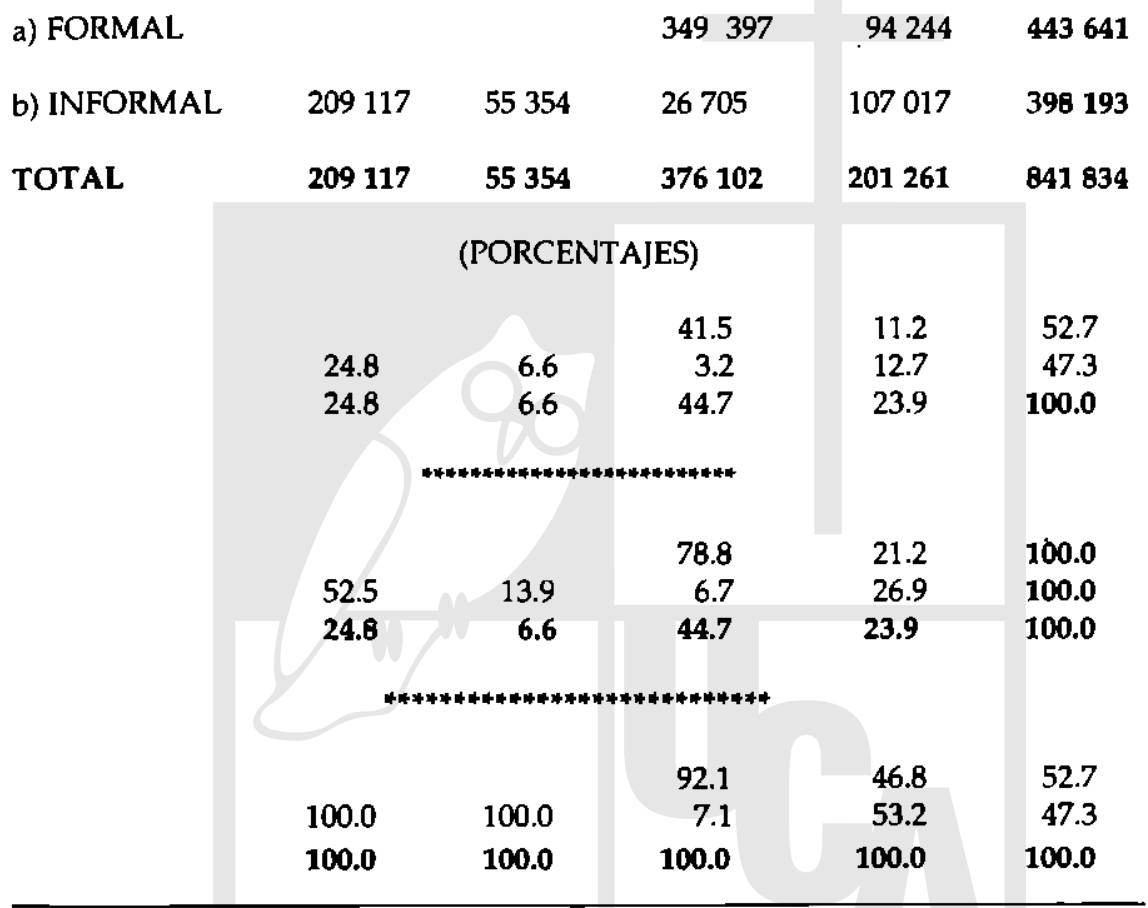

despedir o disminuir las horas de trabajo de los así contratados informalmente.

El despido es la causa más frecuente de los conflictos individuales, lo cual es una manera de manejar la temporalidad del compromiso con mayor arbitrariedad. Para 1993, los conflictos individuales 
tuvieron un promedio de 6 casos al día. De un total de 1893 casos se resolvieron por arreglo económico la mayoría de ellos.

CUADRO No. 3

SERVICIOS CONTRATADOS POR LAS EMPRESAS

\begin{tabular}{|l|l|}
\hline Concepto: & $\%$ \\
\hline Reparación y mantenimiento & 25 \\
\hline Pago a subcontratistas & 60 \\
\hline Arrendamiento maq. y eq. & 22.5 \\
\hline Costes de transporte propio & 12.5 \\
\hline Costos de transp. arrendado & 12.5 \\
\hline Alquiler edificios y terreno & 18 \\
\hline Seguro & 63 \\
\hline Otros costos & 25 \\
\hline
\end{tabular}

Fuente: Arreola y Candray, 1994

Otra forma que las empresas utilizan para usar la fuerza de trabajo informal (por las ventajas de la temporalidad es la subcontratación con unidades productivas informales o que reducen la gestión directa de contratación y las cargas salariales y de prestaciones directas al trabajador. El Cuadro No. 2 (Arriola, 1994) muestra la importancia de esta forma de contratación:

De esta manera los preparativos que hace la economía para incorporarse a las tareas de la globalización dependen de la conservación de los mercados fuertemente basados en el trabajo informalizado y acentuando cada vez más la temporalidad de la contratación de la fuerza de trabajo, rasgo que ya estaba presente en la organización productiva de la agro-exportación y en la que se basa la acumulación de 
la economía cafetalera. No aceptar los costos de la reproducción del trabajador será la continuidad de la economía de El Salvador en un período de modernización y globalización.

\section{El universo subjetivo y la fractura del movimiento laboral sindical}

T a tendencia a usar como antes la fuerza de trabajo es una tenLdencia muy fuerte. Al menos tiende a mentenerse hasta el momento ya que no se ha iniciado la reconversión industrial y agro-industrial, ni han avanzado lo suficiente las nuevas actividades del sector servicios, ni el desarrollo de la maquila tiene un ritmo muy acelerado. Esto es congruente con el hecho de que las tendencias sindicales también han variado muy poco en las formas de comportamiento y mantiene formas y rutinas de conflicto similares a las del pasado inmediato.

Los sindicatos muestran signos de debilidad organizativa, incompetencia operativa, ineficiencia en el campo sindical, obsolescencia en las rutinas de protesta, atomización, escasa capacidad de convocatoria, líderes sin legitimidad y poco representativos, división ideológica y otros. La agitación laboral se desarrolla en medio del deterioro acelerado de las condiciones de vida obrera, de debilidad sindical, crecimiento económico y preparación para un nuevo proyecto de modernización.

Las movilizaciones obreras en las zonas maquiladoras y de los empleados públicos y algunas empresas privadas en las zonas urbanas de los últimos dos años han sido consideradas por el gobiemo e izquierdas como importantes componentes de ingobernabilidad. En esta fase de pacificación y construcción de la democracia, la movilización sindical a la usanza anterior es rechazada por los que buscan afianzar el nuevo orden social y político, desde las izquierdas y las derechas. ¿Puede un movimiento tan desgastado en un entorno de crecimiento volver ingobernable a un gobierno que aún está fortalecido por los acuerdos de paz y un acuerdo nacional para el crecimiento económico y la democratización? ¿O es necesario mantener la misma forma de obediencia de esta mano de obra tan abundante y activa?

Hasta el momento la reacción de los sindicatos a esta situación 
muestra la tradicional orientación histórica de su acción. Por un lado, mantiene el caracter contestario frente a los problemas y, por otro, refuerza el colaboracionismo estatal y, ahora con mucha más intensidad que antes, empresarial. Este último ahora presenta más definición en sus estructuras y presencia adquiriendo las características del movimiento solidarista que proviene de Costa Rica y que consiste en desarrollar las relaciones obrero patronales sin intervención estatal, directamente con las empresas.

Ambas facetas del movimiento sindical son poco propositivas y mantienen niveles altos de ideologización. Los sindicatos de izquierda pasan ahora por un proceso de autonomización de los partidos políticos aunque tienen muchas dificultades para hacerlo. A pesar de la decisión y ya de haber adoptado medidas visibles hacia este propósito, la idea de que el sindicato es un "agente revolucionario" cuyo fin básico es la formación de la "conciencia de clase" y la convertibilidad en fuerza política revolucionaria.

La turbulencia obrera de los 90 tiene lugar en un momento de ausencia de crisis económica. Los indicadores muestran, por el contario, importantes tasas de recuperación y de crecimiento nunca antes alcanzadas. En este cuadro optimista, sin embargo, los empleados públicos y obreros industriales sufren impactos crecientes e incomprensibles en forma de despidos no indemnizados; contracción de los salarios; ausencia, estancamiento o desaparición de prestaciones sociales; desempleo y amenaza permanente de desempleo; pérdida real del poder adquisitivo y deterioro en el nivel de vida frente a poco significativos aumentos al salario mínimo y al alza de los precios y servicios (luz eléctrica, agua, transporte y otros) sin que las organizaciones sindicales puedan evitarlo.

\section{a. La acción sindical en los $\mathbf{8 0}$}

Las diferencias de movilización no son nuevas ni distintas, por el momento. Las dos corrientes que han existido desde los orígenes del movimiento continúan presentes como lo hicieron en la década pasada, no obstante el clima de guerra.

En los primeros años de los ochenta las dos tendencias históricas existieron bajo las siguientes siglas: por la tendencia estatalista: la Unidad Popular Democrática (UPD) —-formada por el LADSL- 
y por la tendencia autonomista con referencia al estado pero no del partido revolucionario, el MOVIMIENTO UNITARIO SINDICAL Y GREMIAL DE EL SALVADOR (MUSYGES). Ambas tendencias presentaron como objetivo estratégico la superación de la guerra y de la crisis social y económica de El Salvador. Ambas plantearon el "diálogo" y la "solución política".

Ambas tendencias crearon en el 86 el organismo unitario de mayor significación en la unidad orgánica del movimiento laboral, de la segunda mitad del siglo, bajo las siglas de UNIDAD NACIONAL DE TRABAJADORES SALVADOREN̄OS -UNTS-. Estuvo integrada por organizaciones sindicales, gremiales, campesinas y cooperativas que se inscribían en distintas tendencias ideológicas.

El LADSL y el gobiemo reaccionaron en contra de la UNTS (que, además de su fuerza propia, contaba con el apoyo de partidos políticos, iglesias, etc.), organizando sindicatos paralelos en los lugares de trabajo, organismos de unidad competitivos a la UNTS (como la UNOC) y realizando trabajos para desintegrarla orgánicamente. Las principales organizaciones sindicales de la tendencia estatalista abandonaron rapidamente la UNTS, la cual se transforma, con gran rapidez, en una organización de política unitaria popular incorporando a comités de derechos humanos, de familiares de desaparecidos, de desempleados y de estudiantes universitarios.

En este período, en síntesis, el movimiento sindical mostró posibilidades de romper con una de las pautas de cultura política más característica del esquema sindical de la segunda post-guerra mundial: su orientación estatal. Las dos tendencias históricas redefinen su vinculación con el estado desde posiciones más autónomas y construyen, de una forma muy pragmática, la relación entre economía y política, entre reinvidicaciones y condiciones generales sociales, entre lo corporativo y lo político. Ambas aprendieron en la década de los ochenta la necesidad de actuar con independencia delos partidos y del estado. Esta lección tratarán de profundizarla durante los 90 .

\section{b. Las tendencias sindicales de post-guerra en los 90}

Se requiere que la nueva restructuración económica e industria 
y la reforma estatal avance más para mayores definiciones sindicales. Debe definirse mejor la política de desarrollo industrial y empresarial para cambiar las antiguas relaciones obrero-patronales.

El "liberalismo del mercado" y la privatización formarán una nueva visión empresarial en el país y esto también imapactará en las relaciones obero patronales. Por el momento, en la actualidad, ante la elevación de la productividad y la capacidad competitiva que comienza a mostrarse en la apertura comercial, los trabajadores, sin cambios reales a nivel e las relaciones propiamente industriales, continúan sintiendo solo el abuso de los empresarios en la intensidad de las jornadas de trabajo y las dificultades de las condiciones de trabajo.

No hay parámetros para repensar los impactos de la productividad, que aún no ha variado, como para alterar las anteriores relaciones patronales. Las empresas plantean una flexibilización de las relaciones de trabajo, mejorar las condiciones de inversión y realizar ajustes de personal y de salarios, a la baja. Las empresas aún no han hecho cambios interno y posponen el enfrentamiento con la competencia internacional y por lo tanto no sabe, hasta el momento, los límites de la productividad que tiene que lograr.

En muchas empresas se expresa el propósito del período: $L a$ flexibilización unilateral o sea eliminar la intervención sindical en la regulación del uso de la fuerza de trabajo. Tiende a hacer desaparecer la bilateralidad en las relaciones laborales y a cambiarse las pautas de organización sindical.

El sindicalismo, de esta forma, se encuentra en un proceso de franca refundación o reconversión. En la actualidad, son muy reconocibles: a) los desplazamientos y diferenciaciones ideológicos y políticos entre los distintos sectores sindicales (existen cinco grandes agrupaciones sindicales a nivel de federaciones o confederaciones con marcadas preferencias políticas); b) las redefiniciones de las relaciones entre los sindicatos y los partidos políticos (unos, los sindicatos de izquierda fundamentalmente, se han declarado independientes; otros más cercanos a los partidos de derecha o al mismo estado y otros se acercan cada vez más a las zonas de influencia patronal; y c) entre los sindicatos y otras instancias de la sociedad civil y el estado. 
Se percibe, por un lado, el fortalecimiento de un sindicalismo pro-empresarial, una línea de fortalecimiento neo-corporativo y una tendencia hacia la construcción de un sindicalismo autónomo. Ninguna de estas tendencias puede tener un proyecto definido frente a una modemización que no avanza y tampoco tienen una posición clara frente al proyecto neoliberal. Todas son débiles y no representan con exactitud los movimientos profundos de las motivaciones laborales después de la guerra interna.

El sindicalismo solidarista trata de eliminar la participación del estado en las relaciones de trabajo, negociando directamente con los empresarios al margen del Código del Trabajo, privilegiando la contratación individual por sobre el colectivo. También tiende a nulificar o disminuir el derecho a huelga mientras plantea el establecimiento de convenios o compromisos de productividad en forma individual con los trabajadores. Este movimiento es silencioso en su crecimiento pero ya es un considerable número de grandes empresas que han incorporado esta forma organizativa con relativo éxito. Con esta experiencia, se ha dado una real trastocación de la libertad de asociación y las posibilidades de aumentar el raquítico número de contratos colectivos en el campo laboral general tiene muy pocas posibilidades de crecer.

Por otra parte, el neocorporativismo arenero trata de ser una ruta hacia el sindicalismo de esta fase: persigue mantener a los trabajadores en torno del estado como base de apoyo y de acuerdo a relaciones clientelistas. Los obreros son considerados como una masa electoral y como base para fortalecer al gobierno en momentos conflictivos o de crisis. Sus promotores hablan de ser "factores de gobernabilidad". Esta tendencia se relaciona con el partido de derecha en el gobierno y, cada vez, se aproxima a tener una relación directa con la presidencia de la república. Los líderes de esta tendencia provienen de la izquierda o de movimientos centristas y son considerados como dirigentes desgastados y corruptos.

El movimiento sindical por la autonomía con relación a la empresa, al estado y a los partidos políticos está compuesto por los provinientes de la izquierda. Han dado pasos hacia la renovación de sus cuadros dirigentes y han desplazado a los líderes anteriores que estaban muy identificados con los partidos y las luchas políti- 
cas. No obstante, han entrado en un proceso de aislacionismo y de inmovilismo al perder los vínculos con el centro que le procuraba el dinamismo para su acción y por no comprender muy bien, como el resto de tendencias, la actual situación económica del país. Han tenido problemas con sus mismos cuadros administrativos centrales y aún no plantean las formas organizativas para su refundación ni elaboran planes de acción definidos.

\section{Bibliografía}

Anner, Mark y Carolina Quinteros. 1994. El sindicalismo salvadoreño en la postguerra: reflexiones preliminares. San Salvador: Ponencia al IX Congreso Centroamericano de Sociología, (mimeo). (Julio).

Arriola P., Joaquín. 1995. El sindicalismo salvadoreño en transición. San Salvador: (mimeo).

Arriola P., Joaquín. 1995. Diagnóstico económico del marco de relaciones laborales. San Salvador: CENTRA. (mimeo).

Arriola P., Joaquín. y José Antonio Candray Alvarado. 1994. Derechos Prohibidos. Negociación colectiva y sindicatos en El Salvador. San Salvador: UCA.

Arriola P., Joaquín. y José Víctor Aguilar Guillén. 1994. El movimiento sindical y la integración regional. San Salvador: UCA. (Mimeo).

Bensusan Areqous, Graciela. 1992. Las relaciones laborales y el tratado de libre comercio. México D. F.: Miguel Angel Porrúa, Grupo Editorial/FLACSO, Sede México.

Briones, Carlos. 1994. Dinámicn socio-económica y gobernabilidad: la administración Cristiani, 1989-1995. San Salvador: FLACSO, Programa El Salvador. (Mimeo)

Canales, Cecilia M., Ana M. Rivas P. y Carlos M. Guerra F. 1994. Caracterización de la segmentación del mercado de trabajo en El Salvador. San Salvador: UCA. (Tesis de licenciatura en Economía).

CENITEC. 1992. Migración y remesas. Una evaluación de su impacto en la economía salvadoreña. En: "Política Económica". No. 11. Febrero-marzo. San Salvador: Cenitec/Dies.

CENITEC. 1993. La crisis del sistema previsional de El Salvador: situación financiera del ISSS y el INPEP. En: "Polílica Económica". No. 20. Septiembre-octubre. San Salvador: Cenitec/Dies.

CENTRA. 1993. La transformación del movimiento sindical salvadoreño en el proceso de transicion. San Salvador: Centra (mimeo).

Cruz P. Edgar, Laura P. Cruz P. y Marvin A. González. 1989. Empleo, salarios y organización industrial: un instrumento de verificación de las hipólesis de segmentación 
de los mercados de Irabajo. El caso de la manufaclura salvadoreña. San Salvador: UCA. (Tesis de licenciatura en Economía).

Dennery, Louis Gerard. 1994. Bases de las relaciones laborales: perspectivas en El Salvador. En: Revista "Realidad". San Salvador: UCA.

Departamento de Economía-UCA. 1995. ¿Qué modelo económico y qué modelo de sociedad queremos? En: ECA. Año L. No. 555-556. San Salvador: UCA.

Fundación Friedriech Ebert (FES), El Salvador. 1994. Informe Laboral: 1993. San Salvador: FES. (Junio)

Fundación Friedriech Ebert (FES), El Salvador. 1995. Informe laboral: 1994. San Salvador: FES. (Abril)

Gorz, Andre. 1995. Metamorfosis del trabajo. Madrid: Editorial Sistema.

Mena, David. 1993. ¿Logrará el sindicalismo un proyecto propio? En: Tendencias. No. 23. Septiembre. San Salvador.

Mena, David. 1995. Las reformas a los códigos laborales en El Salvador. En: Ruptura de los relaciones laborales: Argentina, Brasil, Colombia, Costa Rica, Ecuador, El Salvador, Estados Unidos, México, Paraguay. (Coord. Manfred Wannofell). Caracas: FES (México) y Nueva Sociedad.

Mendoza O., Ricardo (ed.). 1994. Código de Trabajo. Con reformas incorporadas (hasta mayo de 1994). Tomo I. San Salvador: Editorial Jurídica Salvadoreña.

Noticia, La. 1995. La corrupción mantiene en estado agónico al sindicalismo. San Salvador. (Sábado 3 de Junio).

Portes, Alejandro. 1995. En torno a la informalidad: ensayos sobre teoria y medición de la economía no regulada. México D. F.: Miguel Angel Porrúa, Grupo Editorial/ FLACSO, Sede México.

Proceso. 1994. Acercamientos obrero-empresariales. Año 15. No. 640. Diciembre. San Salvador: CIDAI/UCA.

Procuraduria para la Defensa de los Derechos Humanos. 1993. Mapa del movimiento laboral de El Salvador. San Salvador: PDH. (Mimeo).

Ruiz, Marisol y Gilberto García. 1995. Condiciones laborales de menores en las plantas de la maquila coreana y taiwanesa en El Salvador. San Salvador: CENTRA/ UITA. (mimeo). 